\title{
Shaping the resonance. Sympathetic strings in Hindustani classical instruments
}

Stephanie Weisser and Matthias Demoucron

Citation: Proc. Mtgs. Acoust. 15, 035006 (2012); doi: 10.1121/1.4896467

View online: https://doi.org/10.1121/1.4896467

View Table of Contents: https://asa.scitation.org/toc/pma/15/1

Published by the Acoustical Society of America

\section{ARTICLES YOU MAY BE INTERESTED IN}

Sitar spectrum properties

The Journal of the Acoustical Society of America 71, S83 (1982); https://doi.org/10.1121/1.2019587

Perception and orchestration of melody, harmony and rhythm on instruments with 'chikari' strings

Proceedings of Meetings on Acoustics 19, 035052 (2013); https://doi.org/10.1121/1.4799602

Shaping the resonance. Sympathetic strings in Hindustani classical instruments

The Journal of the Acoustical Society of America 131, 3330 (2012); https://doi.org/10.1121/1.4708462

Extending and abstracting sitar acoustics in performance.

The Journal of the Acoustical Society of America 127, 2011 (2010); https://doi.org/10.1121/1.3385227

Modeling the dynamics of a vibrating string with a finite distributed unilateral constraint: Application to the sitar The Journal of the Acoustical Society of America 125, 3673 (2009); https://doi.org/10.1121/1.3123403

A vibrating sitar string: Modeling the 3D dynamics of a plucked string impacting a spatial obstacle with friction The Journal of the Acoustical Society of America 123, 3380 (2008); https://doi.org/10.1121/1.2934018

\section{Advance your science and career as a member of the}




\section{Proceedings of Meetings on Acoustics}

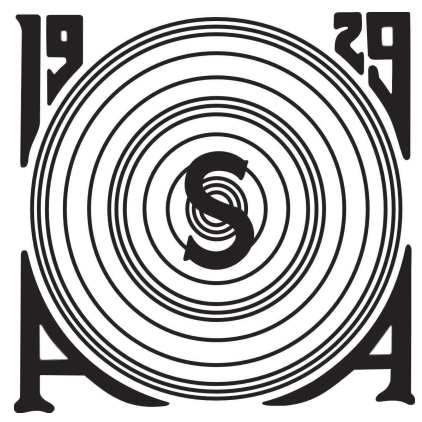

\section{3rd Meeting Acoustical Society of America/ACOUSTICS 2012 HONG KONG Hong Kong \\ 13 - 18 May 2012}

\section{Session 2pMU: Musical Acoustics}

\section{2pMU6. Shaping the resonance. Sympathetic strings in Hindustani classical instruments}

Stephanie Weisser* and Matthias Demoucron

*Corresponding author's address: Musical Instruments Museum, Brussels, 1000, Brussels, Belgium, stephanieweisser@gmail. com

Most chordophones of the contemporary classical Hindustani tradition are characterized by the presence of numerous sympathetic strings (taraf), sometimes up to over 30. Generally tuned according to the rag, they are inserted within the handle of the plucked lutes sitar and sarod, and next to and below the main strings of the bowed fiddle sarangi. In some cases (eg. some of sarangi's taraf and all of the sitar's taraf) are also equipped with a curved bridge, increasing the spectral richness of the sounds produced by these strings. Players consider the taraf's response as fundamental to the instrument's sound. Based on field recordings realized at the ITC Sangeet Research Academy (Kolkata, India) this study aims to determine the contribution of these strings to the resulting sound of the different instruments and settings. Acoustical analyses are complemented with ethnomusicological analyses, in order to evaluate the taraf's aesthetic, musical and perceptual role.

Published by the Acoustical Society of America through the American Institute of Physics 


\section{Introduction}

Hindustani classical music is a very rich and complex tradition. Among the instruments, the chordophones (tata vadya) played a prominent role in the history and development of Hindustani classical music. Nowadays, the sitar, sarod and to a lesser extent the sarangi (Figure 1) are the most revered solo melodic instruments and the most widely used in classical performances [Sorell and Narayan 1980, p. 34]. Plucked lutes sitar and sarod as well as bowed fiddle sarangi share a common feature: they comprise sympathetic strings (Figure 2).
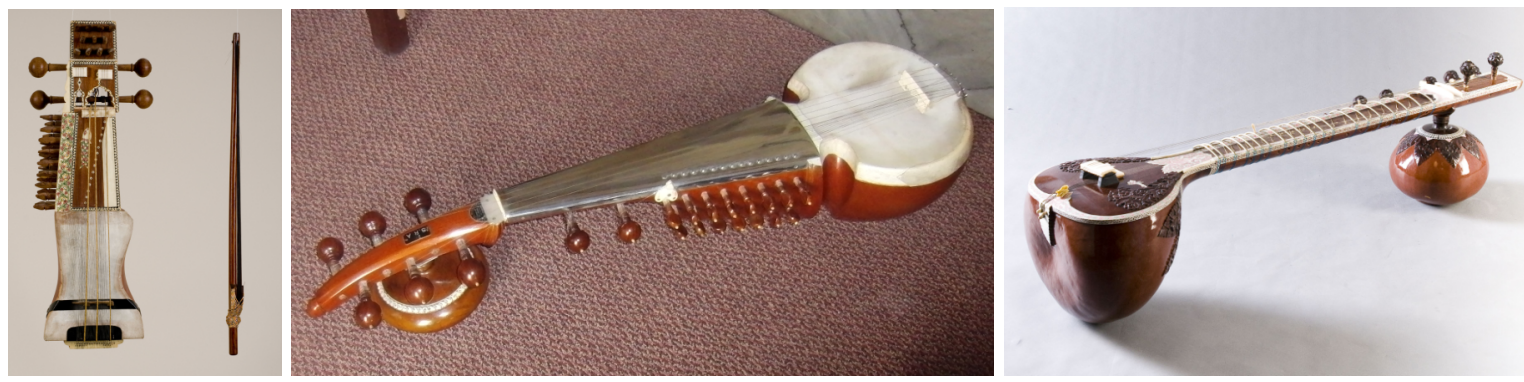

Figure 1. From left to right. Sarangi, Inv. Nr 2010.057, Musical Instruments Museum, Brussels; Sarod, ITC-Sangeet Research Academy, Kolkata, Sitar, Inv Nr. 2007.001, Musical Instruments Museum, Brussels. Left and right photos: S. Egan (C mim; centre: Stéphanie Weisser.

According to iconographic evidence, the introduction of sympathetic strings on Indian instruments is estimated to date back to the beginning of the 17th century [Bohr 1986-7, pp. 55-56]. Nevertheless, its generalization in classical music context is more recent: the sitar became equipped with taraf by the end of the 19th century [Junius 1974, p. 20]. The sarod was elaborated during the second half of the 19th century from the rabab, a Pathan instrument (east of Afghanistan-north of Pakistan) also equipped with taraf strings [McNeil 2004, pp. 11-25, 88-96]. The sarangi, historically associated with singing and dancing courtesans, progressively entered the field of classical music during the 20th century [Qureshi 1997].
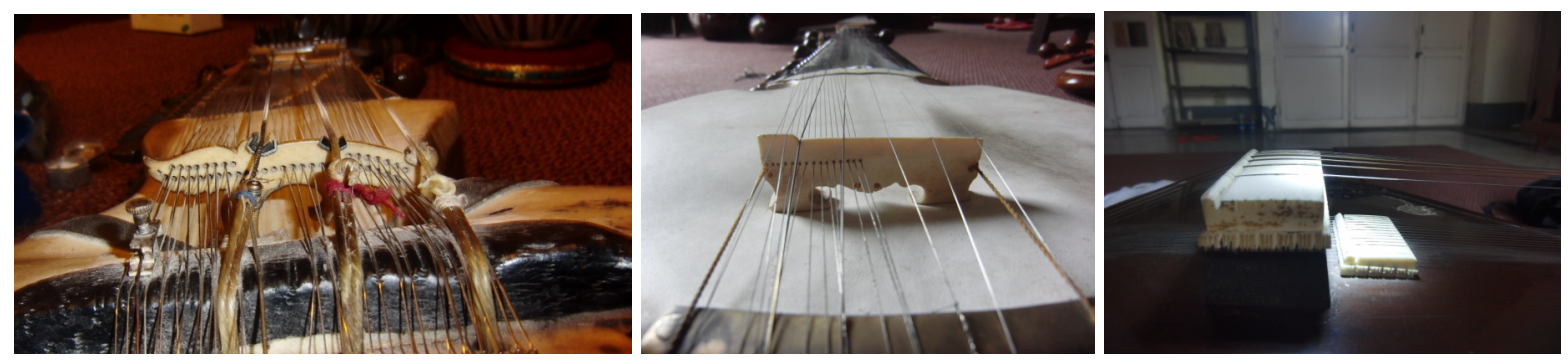

Figure 2. From left to right. Taraf (sympathetic strings) of sarangi, sarod and sitar, ITC-Sangeet Research Academy, Kolkata. Photos: Stéphanie Weisser.

Taraf settings are different according to the instruments, the gharana (socio-aesthetical tradition), and often the personal taste of the player. However, some general remarks can be made, for example regarding the number, material and location (see Table 1). 
Table 1. Taraf settings and characteristics according to instrument type.

\begin{tabular}{|c|c|c|c|}
\hline Taraf setting and characteristic & Sarod & Sitar & Sarangi \\
\hline Material & Metal & Metal & Metal \\
\hline Bridge & $\begin{array}{l}\text { Sharp bridge shared with } \\
\text { playing strings; taraf pass } \\
\text { through holes }\end{array}$ & $\begin{array}{l}\text { Wide and curved, } \\
\text { independent from the } \\
\text { playing strings }\end{array}$ & $\begin{array}{l}\text { Sharp bridge shared with } \\
\text { playing strings; taraf pass } \\
\text { through holes }\end{array}$ \\
\hline Tuning & According to the rag & According to the rag & $\begin{array}{l}\text { According to the rag and } \\
\text { chromatically (all notes) }\end{array}$ \\
\hline Number & $\begin{array}{c}\text { From } 11 \text { to } 15 \text {, grouped in } \\
\text { a single set }\end{array}$ & $\begin{array}{l}\text { From } 11 \text { to } 13, \\
\text { grouped in a single set }\end{array}$ & $\begin{array}{c}\text { Up to over } 35 \text {, grouped in four } \\
\text { sets (two sets sometimes with } \\
\text { additional small curved wide } \\
\text { bridges) }\end{array}$ \\
\hline Location & $\begin{array}{l}\text { In the closed handle and } \\
\text { under the curved frets }{ }^{1}\end{array}$ & $\begin{array}{l}\text { In the closed unfretted } \\
\text { handle, next to the } \\
\text { playing strings }\end{array}$ & $\begin{array}{l}\text { Partly in the open unfretted } \\
\text { handle, partly next to the } \\
\text { playing strings }\end{array}$ \\
\hline
\end{tabular}

In comparison with the wide curved bridge (jawari), the other specific feature of Hindustani chordophones, the taraf strings (and sympathetic strings in general) are scarcely studied from an acoustical point of view, except for Besnainou and Castellengo's paper [1995, p. 60] in which sounds of a sarangi are visualized with spectrograms and taraf effect briefly described as "an echo that makes the sound shimmers" and "wonderfully complex". In musical and musicological literature on Indian music, few mentions of this effect are found, usually limited to the number of sympathetic strings, their location on the instrument and their tuning. Sometimes, their effect on sound is briefly mentioned: "[they] gave a boost to amplification and sustenance" [Raja 2005, p. 297]. However, N. A. Jairazbhoy and A. W. Stone [1963] observed that on the sitar the presence of sympathetic strings may have an important effect on intonation: the sympathetic strings may cause the pitch of the main string to drop rapidly and beats to become audible. They measured "a difference of as much as 20 cents in extreme cases between the pitch at the moment of impact and the levelling of the tone" [Jairazbhoy and Stone 1963]. Priyamvada [2009] also notes that sympathetic strings' response is maximum when the interval between the played sound and the taraf is a unison or an octave, and to a lesser extent a fifth. The author describes the taraf's effect as "a lingering halo of sound", and as a way to "enhance the sound of the instrument" [Priyamvada 2009, vol. 2, p. 379].

From a conceptual point of view, Napier [2003-2004] considers that the "resonant haze of the tarab (sympathetic strings)" is one of the several "basic phenomenon of Indian music". Taraf effect can be considered as one of the way to attain the Indian aesthetic ideal of saturation [Napier 2003-2004, pp. 128-129], defined as the preference for continuity of the melodic line, ornamentation and "a 'sonic depth' or textural richness that must be achieved without compromising the dominance and subtlety of melody" [Ibid., p. 116] - or the fear of the void, to sum it up. Taraf strings are constituent parts of the instruments and the sonorous event. In this paper, their role will be analyzed and evaluated, from musical, perceptual and acoustical points of view.

\section{Material and methods}

Several scholars of the ITC-Sangeet Research Academy (Kolkata, India) were interviewed and recorded. Tones were recorded one by one, first with the taraf's normal setting and second with the

1 Unlike frets in Western instruments, the sitar frets are curved and the musician can control pitch by pulling the string along the fret (the meend technique). The pitch produced with this technique can raise up to a fifth. 
taraf vibrations being stopped by a cloth wrapped around them. Musicians were asked to let each sound vibrate until natural tone extinction occurs before playing the next one. Tuning and rag was left to their choice.

Recordings took place in a sound-proof room of the Academy, with a two-channel Sound Device 702 portable audio recorder and two cardioid MBHO NBNM $440 \mathrm{CL}$ microphones. Interviews took place most of the time before or after the recording sessions. Personal information such as age, musical experience, musical preferences were collected, then open questions about sound and taraf were asked ("What do taraf do?", "What is a good taraf contribution?", etc.) in order to engage in an informal discussion. Information collected in Belgium from Indian musicians on tour or professional European players of Hindustani music were added to the corpus of statements.

About 13 pairs of sounds from one instrument of each type (sarangi, sarod and sitar) were selected, edited with Sound Studio software and analyzed with the Timbre Toolbox [Peeters et al. 2011] for calculation of the following timbre descriptors: (1) Log-Attack-Time; (2) Spectral Centroid (Mean and Standard Deviation); (3) Tristimulus 1, 2 and 3; (4) Decrease Slope. Fundamental Frequency was calculated using the IRCAM's software Audiosculpt, and Roughness with MIRToolbox using Vassilakis' model [Lartillot and Toiviainen 2007].

In total, 40 pairs of sounds (with and without taraf) were analyzed and Percentage Increase/Decrease of descriptor values for sounds with and without taraf were calculated (see Table 2). Information from interviews was categorized into three main categories: Intrinsic (related to sound itself), Extrinsic (related to symbolic associations activated by the sounds) and Practical (related to settings, tuning, playing, etc.). The Instrinsic information category, consisting of 56 statements, was subdivided into Information related to global sounds category and Information related to taraf sounds. These two subcategories were further divided according to content (see Table 3).

\section{Results}

Contribution of the taraf to global sounds is noticeable in all calculated descriptors (see Table 2).

Table 2. Percentage Increase/Decrease (unless stated otherwise) in descriptor values due to taraf's contribution, for sarangi, sarod and sitar.

\begin{tabular}{cccc}
\hline Percentage Increase/Decrease & Sarangi & Sarod & Sitar \\
\hline Spectral Centroid (SC) mean/f0 & $+8 \%$ & $-9 \%$ & $+9 \%$ \\
Spectral Centroid (standard deviation) & $+1 \%$ & $-14 \%$ & $+28 \%$ \\
Attack Duration & $+13 \%$ & $+3 \%$ & $-2 \%$ \\
Tristimulus 1 (T1) & $+74 \%$ & $+16 \%$ & $-8 \%$ \\
Tristimulus 2 (T2) & $-12 \%$ & $-5 \%$ & $-5 \%$ \\
$\quad$ Tristimulus 3 (T3) & $+1 \%$ & $-14 \%$ & $+8 \%$ \\
Intervals between F0 with and without & & & \\
taraf (absolute values in cents) & 6.93 & 4.56 & 3.6 \\
F0 with taraf $<$ f0 without taraf (in \% & & & \\
regarding the corpus) & $77 \%$ & $64 \%$ & $31 \%$ \\
$\quad$ Roughness (mean) & $-5 \%$ & $+52 \%$ & $+33 \%$ \\
Roughness (standard deviation) & $+11 \%$ & $+50 \%$ & $+18 \%$ \\
Decrease Slope & N. P. & Increase & Increase \\
\hline
\end{tabular}

SC mean values are raised in sarangi and sitar, but lowered in sarod. The Standard Deviation values for this descriptor are also increased for sarangi and sitar, whereas they are lowered for sarod. Attack duration is more important for sarod and sarangi, but less for sitar. Spectral repartition is changed for all instruments: T1 is increased for sarod and sarangi, T3 for sitar. Roughness (mean) diminishes only for sarangi, but increases for sitar and sarangi. Standard Deviation of the Roughness 
increases for all instruments. T2 decreases for all instruments. Only these last two descriptors are influenced in a similar way by the presence taraf for all instruments.

Content analysis of players' information shows that most of the information related to the Intrinsic category regards sound color (14 statements for Global sound category, 8 on Taraf sound category, see Table 3), followed by non-timbral sound features (10 statements on global sounds, 10 on taraf sound). The latter were mostly expressed by sarod players or sarodiya (11 statements), whereas statements focusing on sound color were in majority (9) expressed by sitar (6) and sarangi (3) players.

Table 3 Content-analysis table of instrinsic information from musicians' interviews, with number of statements for each category and example(s).

\begin{tabular}{|c|c|c|}
\hline \multirow[t]{3}{*}{$\begin{array}{l}\text { 1.1. Global sound } \\
(30)\end{array}$} & 1.1.1 Non-timbral feature (10) & $\begin{array}{l}\text { "Taraf increase the resonance/sustain"(3)/"the duration of } \\
\text { the sound"(4) }\end{array}$ \\
\hline & 1.1.2. Change sound colour (14) & $\begin{array}{l}\text { "Taraf bring extra vibration to/enrich the sound"(3)/"bring } \\
\text { sweetness/softness to the sound" }(2)\end{array}$ \\
\hline & $\begin{array}{l}\text { 1.1.3. Change quality/beauty } \\
\text { (6) }\end{array}$ & $\begin{array}{l}\text { "Taraf make the sound very beautiful/Sound with taraf is } \\
\text { very good"( } 6)\end{array}$ \\
\hline \multirow[t]{3}{*}{$\begin{array}{l}\text { 1.2. Taraf sound } \\
\text { (26) }\end{array}$} & 1.2.1. Non-timbral feature (10) & $\begin{array}{l}\text { "Taraf must sound for a long time"/"as loud as possible" } \\
\text { (3) /"not too much" (4) }\end{array}$ \\
\hline & 1.2.2. Sound quality (8) & "Taraf must sound mellow" (2), “echo-like" (1) \\
\hline & $\begin{array}{l}\text { 1.2.3. Heterogenic responses } \\
\text { (8) }\end{array}$ & $\begin{array}{l}\text { "Some Taraf respond more" (6)/“All taraf must respond } \\
\text { equally" (2) }\end{array}$ \\
\hline
\end{tabular}

\section{Discussion}

The differences in statements according to an instrument's type (sarod vs. sitar and sarangi) underline the fact that taraf play a different role according to the presence or absence of jawari (wide curved bridge $)^{2}$ for all or some of them. This difference is also noticeable in the desired intensity of the taraf contribution (part of category 1.2.2): most sarodiya (three out of the four players who explicitly mentioned this feature) want a maximal or loud contribution of the taraf, whereas all the four sitar and sarangi players desire a more controlled (limited) contribution. Contributions of taraf to the sound color of the global sound are evoked in quite diverse terms. The most frequent statement relates to "extra vibration/enrichment of the sound" (two sitariya, one sarangiya), followed by "taraf bring sweetness/softness to the sound" (one sitariya, one sarangiya).

Some statements of the Intrinsic category seem contradictory: "taraf make the sound rounder" (sarodiya) vs "taraf improve the clarity of the sound" (sarangiya). If this contradiction can be, once again, explained by the presence of the jawari, the following is more intriguing. Two sitariya stated

$2 \quad$ Almost all sarodiya interviewed (5 out of 7) are studying under the guidance of Pandit Buddhadev Das Gupta (Shahjahanpur Gharana). In this tradition, sarod is not equipped with jawari, in opposition with the Maihar Gharana, for example. One of the most famous tenants of the latter, Ustad Ali Akhbar Khan, even considered that instruments played by these two gharana were so different that they should be spelled differently, using sarode instead of sarod (D. Trasoff, personal communication, October 2011). It can also be noted that one of the sarangi players interviewed, Pandit Dhruba Ghosh, took away several taraf as well as the two jawari on his instruments. 
respectively "taraf bring lightness to sounds" and "taraf make the sound deeper". However, conjunct analyses can explain this apparent contradiction: the "roundness" brought to the sound by taraf according to a sarod player (vs the brought "clarity" according to a sarangi player) can be related to the lowering of the SC - related to brightness - for sarod.

Other correlations between measurements and statements can be made: the "extra-vibration" noted by sarangi and sitar players can be correlated with the increase of roughness for sounds with taraf. The lowering of Standard Deviation of spectral centroid (SC) measurements for the sarod can indicate a more homogeneous response of the taraf (or a 'homogenizing' effect on global sounds due to the contribution of the taraf) for this instrument, and can be linked with the two statements in favor of homogeneous responses (category 1.2.3). The increase of $\mathrm{T} 1$ for sarod can be linked with statements of two sarodiya, who consider that low-pitched strings generate better taraf responses than high-pitched ones, and that taraf tuned in unison respond the best. As for sarangi, the increase of T1 could also be correlated with the rather unexpected lowering of mean roughness, as the latter would be much more important in case of spectral enhancement in higher frequencies (as the critical bandwidth increases with frequency) than in lower ones.

Eventually, the increase of Standard Deviation for Roughness measurements can also be correlated to the "extra life" brought to the sound by the taraf. Changes in fundamental frequencies (f0) can also be directly linked with the total number of sympathetic strings: the more numerous the taraf (as in sarangi), the more important the change of f0.

\section{Conclusions}

Acoustical and ethnomusicological information confirm that taraf are indeed a very important feature of the instruments they are part of. The taraf's effects vary deeply according to instruments, settings and played notes; so far, it does not seem possible to categorize specific behaviours, within instrument types, according to registers, scale degrees nor sounds produced by open strings/fingering. This underlines the variability of non-western, non-standardized instruments, and also the important degree of personal "fine-adjustment" of the timbral characteristics of instrumental sounds by the players.

In a North-Indian classical music performance, all the sonorous possibilities are explored. From sounds lasting until their natural extinction to sounds played with extreme speed, from the lowest pitch possible on an instrument to the highest, from softest to loudest (pitch, speed and loudness usually increasing together from introductory part alap to climatic ending jhala), musicians use the entire range of sounds their instrument can produce - with their timbral diversity. Such variability needs to be taken into consideration, in ethnomusicological studies as well as in acoustical studies, as this variety is a key feature of this fascinating musical system.

\section{Acknowledgements}

The authors would like to thank all the players and informants who participated to this study, in Belgium and in India. The fieldwork was supported by a Grant for Mobility in Scientific Research from the National Fund for Scientific Research (FNRS-FRS), Belgium. This work is funded by the Belgian Science Policy Office, in the framework of the Action 1 Project "Timbre Modifiers in Chordophones" (Musical Instruments Museum), and the EmcoMetecca project supported by the Flemish Government.

\section{References}

Besnainou, C., and Castellengo, M. (1995) "De la résonance, une étude acoustique du phénomène sympathique", in Amour et sympathie: actes du colloque sur les instruments à cordes sympathiques, Limoges, 28-29 novembre 1992, Editions Ensemble Baroque de Limoges, 53-61. 
Bohr, J. (1985-1986). "The Voice of Sarangi," Quarterly Journal of the National Centre for the Performing Arts, Bombay Special Issue XV-XVI.

Jairazbhoy, N. A., and Stone, A. W. (1963). "Intonation in Present-Day North Indian Classical Music," Bulletin of the School of Oriental and African Studies 26/1, 119-32.

Junius, M. (1974) The Sitar. The instrument and its Technique, Wilhelmshaven: Heinrichshofen.

Lartillot, O., and Toiviainen, P. (2007). "A Matlab Toolbox for Musical Feature Extraction from Audio," in Proceedings of the 10th International Conference on Digital Audio Effects (DAFx-07), Bordeaux, France, September 10-15.

McNeill, A. (2004). Inventing the Sarod. A cultural history. Calcutta: Seagull.

Napier, J. (2003-2004). “An Old Tradition but a Very New Practice: Accompaniment and the Saturation Aesthetic in Indian Music," Asian Music 35/1, 115-34.

Peeters, G., Giordano, B. L., Susini, P., Misdariis, N., and McAdams, S. (2011). "The Timbre Toolbox: Extracting audio descriptors from musical signals," JASA 130, 2902-16.

Priyamvada, A. (2009). Encyclopaedia of Indian Musical Instruments, New Delhi: Anmol, 3 vol.

Qureshi, R.B (1997). “The Indian Sarangi: Sound of Affect, Site of Contest," Yearbook for Traditional Music 29, 1-38.

Raja, D.S. (2005). Hindustani Music. A tradition in transition, New Delhi: Printworld.

Sorrell, N., and Narayan, R. (1980). Indian Music in performance: a practical introduction, Manchester, Manchester University Press. 